\title{
ARRANJO PRODUTIVO LOCAL DA FRUTICULTURA IRRIGADA DO VALE DO SUBMÉDIO DO SÃO FRANCISCO, PERNAMBUCO/BAHIA: FLUXOS COMERCIAIS E DINAMISMO LOCAL
}

\author{
Éder Lira de Souza Leão* \\ Lúcia Maria Góes Moutinho** \\ Luís Henrique Romani Campos****
}

RESUMO: O Vale do Submédio do São Francisco (VSMSF) é um importante território que abrange municípios de Pernambuco e Bahia. A dinâmica econômica local é promovida pela Fruticultura Irrigada e Vitivinicultura, formando importantes arranjos produtivos e inovativos. A proposta deste artigo é analisar os fluxos comerciais da atividade frutícola, pois uma característica importante de um Arranjo Produtivo Local (APL) é a sua relação econômica, política e institucional com o que está fora do território. Este APL está inserido em um contexto de mercado nacional e global. A parte teórica aborda principalmente os argumentos e metodologias da RedeSist/UFRJ. Também são utilizados bancos de dados institucionais para obtenção de informações sobre produção, fluxo comercial nacional e internacional, censo agropecuário. Esses dados analisam os fluxos comerciais da manga, uva, coco-da-baía e melão. No fluxo internacional, percebe-se que este APL é suscetível às mudanças no cenário econômico dos principais demandantes de seus produtos - Estados Unidos e Países Europeus - causando, portanto, uma dependência. A análise do fluxo interestadual demonstra que não é apenas uma alternativa em períodos de crise internacional, mas também um mercado potencial. $\mathrm{O}$ estudo conclui que outros gargalos freiam seu desenvolvimento, como ausência de melhorias na logística e política de inovação.

PALAVRAS-CHAVE: Arranjo Produtivo Local; Fluxos Comerciais; Vale do Submédio do São Francisco.

LOCAL PRODUCTION ARRANGEMENT OF IRRIGATED FRUIT CULTURE IN THE LOWER SÃO FRANCISCO RIVER, PERNAMBUCO/BAHIA: COMMERCIAL FLOWS AND LOCAL DYNAMICS

\footnotetext{
Docente no Curso de Ciências Econômicas da UFRPE/UAST e Mestre em Administração e Desenvolvimento Rural (PADR-UFRPE). E-mail: eder1983@gmail.com

** Docente do Curso de Ciências Econômicas da Universidade Federal Rural de Pernambuco (UFRPE) e do Programa de Pós-Graduação em Administração e Desenvolvimento Rural (PADR), Brasil.

${ }^{* * *}$ Pesquisador e Diretor de Pesquisas Sociais da Fundação Joaquim Nabuco (FUNDAJ), Brasil.
} 
ABSTRACT: The lower São Francisco river is an important area comprising municipalities in the states of Pernambuco and Bahia, Brazil. Local economical dynamics enhances Irrigated Fruit Culture and Grape Culture with important production and innovation arrangements. Current article analyzes the commercial flux of fruit culture activities since an important characteristic of the Local Production Arrangement (LPA) comprises the economic, political and institutional relation with territory outsiders. LPA is inserted within the context of the national and global market. The theoretical section appropriates mainly the RedeSist/UFRJ arguments and methodologies. Institutional data bases are used to obtain information of produce, national and international commercial flux and agriculture and livestock census. Data analyze the commercial fluxes of mangoes, grapes, coconuts and melons. LPA within the international flux is susceptible to changes in the economic scenario of the main consumers of the products, namely, the United States and European countries, causing dependence. Analysis of the interstate flow shows that it is not merely an alternative in periods of international crisis but also a potential market. Results show that other issues hinder development, such as the absence of improvements in logistics and innovation policies.

KEY WORDS: Local Production Arrangement; Commercial Fluxes; Lower São Francisco River.

\section{INTRODUÇÃO}

O presente artigo discute se os fluxos comerciais - interestaduais e internacionais - do Arranjo Produtivo de Fruticultura Irrigada do Vale do Submédio do São Francisco (VSMSF) influenciam no desenvolvimento local deste território.

Estudar Arranjos Produtivos Locais (APL) e, em particular, do VSMSF, pressupõe um olhar sobre os APL como abordagens estratégicas para o desenvolvimento da base econômica e social do território, tornando-se, nesse âmbito, instrumentos analíticos para a governança local, mas principalmente, a inovação, ferramenta para gerar os elementos básicos do desenvolvimento local. Nessa direção, inclui o interesse de articular e executar ações e políticas públicas e sociais que priorizem as características intrínsecas dos atores locais e dinamizem não somente a economia, mas inclusive os fatores intersubjetivos e interdependentes do território. 
O Brasil possui dezenas de experiências de APL identificadas por várias instituições públicas e privadas, mas um estudo mais amplo foi realizado pela Rede de Pesquisa em Sistemas e Arranjos Produtivos e Inovativos Locais (RedeSist), que visou analisar esses mapeamentos e políticas para APL entre 2009 e $2010^{4}$.

O território do Vale do Submédio do São Francisco funciona de forma sistêmica, pois agrega espaços geográficos de dois Estados do Nordeste, além de formar com os dois principais municípios - Juazeiro da Bahia e Petrolina de Pernambuco - uma das maiores conurbações do Semiárido.

Sobre a Fruticultura Irrigada esta se destaca e é escolhida neste estudo porque está inserida em um novo contexto de mercado globalizado ${ }^{5}$, pois este território localiza-se no Semiárido e produz duas commodities importantes, inclusive para a Balança Comercial dos dois Estados, além de aproximadamente $90 \%$ da sua produção ser exportada. Sendo assim, necessita desenvolver laços de cooperação e promover inovação tecnológica para expandir as possibilidades de interação com o mercado internacional (e também nacional), pois na medida em que esse vínculo se amplia globalmente, o território se adapta, transforma, mas não apenas no âmbito comercial, econômico; as mudanças ocorrem também advindas do fluxo de informações e outras dinâmicas que são criadas concomitantemente aos vínculos culturais, históricos e sociais.

O APL estudado se estende por um território histórico, como mencionado acima, ainda que a atuação dos Governos Estaduais e Municipais possa focar nas fronteiras geográficas e delimitações geopolíticas espacialmente demarcadas. Isso não impede parcerias e diálogos entre esses gestores, pois há várias políticas e ações que são realizadas visualizando o território sistêmico.

A abrangência e as intervenções em um APL podem integrar essas fronteiras, pois a formação do APL reflete sua trajetória histórica e aspectos e vínculos formais e informais constituídos por laços socioeconômicos e políticos entre os atores, que por sua vez geram um sentimento de pertencimento àquele espaço com vistas à sustentabilidade e desenvolvimento das atividades locais com características e interesses comuns, ou seja, ao território.

4 Mais informações disponíveis em: http://www.politicaapls.redesist.ie.ufrj.br/.

5 Mas lembrando que não é a única atividade econômica do território, a Vitivinicultura forma um importante Sistema Produtivo Local (VITAL, 2009). 
Além desta introdução, o artigo nas duas primeiras seções apresenta os aspectos teóricos, metodológicos e operacionais do percurso e análise deste estudo. As duas seções seguintes revisam e articulam uma análise dos resultados pesquisados. Por fim, a última seção traz algumas breves conclusões acerca dos pontos destacados no trabalho.

\section{ASPECTOS TEÓRICOS}

\subsection{ARRANJOS PRODUTIVOS LOCAIS}

Primordialmente, um APL surge em um determinado território, aglomerando empreendimentos e instituições voltados para uma mesma atividade econômica ou envolvendo atividades complementares; esta sua formação e evolução refletem as mudanças no território, alterando e integrando sua trajetória histórica, bem como fortalecendo os vínculos sociais e institucionais.

A partir de $2004^{6}$ verificou-se que os APL têm tido uma crescente visibilidade e atenção por parte dos planos e políticas governamentais, além dos próprios atores locais, que passam a enxergar sua região com outras "lentes", consequência de encontros, reuniões, fóruns e outras ações que debatem e articulam questões relativas ao desenvolvimento econômico, político, social e cultural da aglomeração produtiva. Constata-se ainda, que em diversos APL, seus atores - sejam empresários, gestores públicos ou trabalhadores - estão organizados formal ou informalmente em algum tipo de gestão associativa e cooperativa, que se articulam das mais diversas formas em fóruns, redes e federações, associações em órgãos públicos e privados.

Para a RedeSist onde houver empreendimentos, empresas e indivíduos concentrados em um determinado local ou região haverá sempre um arranjo entorno da mesma, relacionando atores, agentes e atividades econômicas comuns. É nesse sentido que se estudaram as relações comerciais do APL para além de suas fronteiras territoriais. A partir dessa abordagem são identificados diversos APL, porém há várias

6 Ano em que foi instituído o Grupo de Trabalho Permanente sobre Arranjos Produtivos Locais (GTP-APL), no âmbito do Governo Federal. Foram reunidas mais de trinta instituições nacionais com atuação de políticas e estudos sobre APL. 
instituições que apoiam e assessoram, conceituam e utilizam critérios diferentes para atuar em um APL (LASTRES; CASSIOLATO, 2005; MOUTINHO et al., 2009a).

A geografia do território e a trajetória histórica do APL explicam em parte sua formação, aglomerando empresas, que em um contexto de proximidade, ganham economias externas; além disso, o ambiente torna-se muito importante por atrair clientes, em busca dos melhores preços e os melhores trabalhadores especializados, que buscam emprego nas diversas firmas instaladas (PAIVA, 2002).

\subsection{FLUXOS COMERCIAIS DOS APL}

As empresas e instituições dos APL têm seus papéis ampliados nas relações econômicas com outros "nichos" de mercado. Analisando o saldo das transações comerciais, e alguns desses arranjos produtivos, percebe-se que são superavitários, outros deficitários, contudo, essa contabilização evidencia as contribuições dos APL para o destino das entradas e saídas dos insumos, produtos e recursos financeiros e de capitais.

A análise do fluxo comercial, especialmente dos APL, poderá identificar possíveis entraves e pontos de estrangulamento nos fluxos comerciais, que atrasam ou bloqueiam seu desenvolvimento, e, uma vez identificados, poderão ser objeto de políticas e ações, em um planejamento conjunto que envolve seus principais atores.

As atividades econômicas agropecuárias identificadas como APL atendem, em princípio, a essas características, pois dispõem de um conjunto de informações mensuradas estatisticamente para regiões e municípios, como: área de cultivo, produção, comércio e emprego, que facilitam a aproximação dos dados para construir a dinâmica do fluxo comercial dos APL, pois estes estão identificados em territórios que transpõem as delimitações do espaço geográfico. O território não é um simples espaço físico, mas uma representação simbólica, subjetiva, construída socialmente com as referências culturais dos que lá vivem (HAESBAERT, 2004).

O APL não é um espaço geográfico ou uma região geopolítica delimitada por um Governo; sua abrangência e atuação transbordam essas áreas físicas determinadas, pois sua formação tange a trajetória histórica e aos aspectos e vínculos institucionais constituídos entre os atores no que concerne à sustentabilidade e ao 
desenvolvimento da localidade com características e interesses comuns. Logo, se percebe que a dificuldade em mensurar as transações e resultados do comércio em um APL é uma tarefa que precede maior estudo e análise.

No entanto, é possível a partir dos Fluxos Comerciais analisar a participação aproximada dos APL na produção e no comércio interestadual e internacional dos Estados da Bahia e Pernambuco. Esta ideia se apoia nos dados secundários do ALICE-Web $^{7}$; das Secretarias da Fazenda dos Estados de Pernambuco e Bahia (SEFAZPE e SEFAZ-BA) - que apresentam informações das transações entre Estados; e do Instituto Brasileiro de Geografia e Estatística (IBGE) - que fornece várias estatísticas atualizadas populacionais e de economia por Municípios e Estados.

A análise da produção e do fluxo comercial interestadual e internacional possibilita identificar e verificar as políticas e ações implementadas pelas diversas esferas institucionais, públicas ou privadas, gerando um entendimento a respeito das melhores formas de ação integrada nos APL.

\section{ASPECTOS METODOLÓGICOS}

O cenário da pesquisa é a região denominada de Vale do Submédio do São Francisco (VSMSF), no Semiárido de Pernambuco e da Bahia, região destacada devido aos investimentos em irrigação, pesquisa, produção, exportação de frutas, hortaliças e vinhos. Os municípios selecionados para o estudo compreendem mais especificamente aqueles identificados em listagens e mapeamentos institucionais, como sendo os mais importantes na composição do APL da Fruticultura Irrigada no Sertão de São Francisco em Pernambuco (Petrolina, Lagoa Grande, Santa Maria da Boa Vista e Orocó) e Bahia (Juazeiro, Casa Nova, Curaçá e Sento Sé). Dada a variedade de frutas cultivadas na região, são consideradas aquelas de maior expressão no comércio interestadual e internacional da região, tais como: Uva, Manga, Melão e Coco-da-baía.

A base conceitual e analítica desse trabalho sobre aglomeração de empresas e sistemas, e arranjos produtivos locais, partiu dos estudos da RedeSist-

\footnotetext{
7 Sistema informatizado do SECEX/MDIC que fornece dados periódicos das exportações e importações de vários bens pelo seu valor free on board (FOB), descentralizados inclusive por Estados.
} 
UFRJ, Cassiolato e Lastres (2005; 2006), e Paiva (2002), em consonância, os dados secundários para análise do panorama internacional, nacional, regional e local do APL foram coletados junto a fontes de instituições: Produção Agrícola Municipal, Pesquisa Pecuária Municipal e Censos Demográfico e Agropecuário do IBGE, Sistema e Análise das Informações de Comércio Exterior (ALICE-Web) da Secretaria de Comércio Exterior/Ministério do Desenvolvimento, Indústria e Comércio Exterior (SECEX/MDIC), Secretaria da Fazenda de Pernambuco e Bahia (SEFAZ-PE e SEFAZBA), e dos dados estatísticos do FAOSTAT da Organização das Nações Unidas para a Agricultura e Alimentação (FAO).

As estatísticas - taxa de crescimento e taxa de proporção - utilizadas neste trabalho são analisadas por aproximação, tendo como referência os procedimentos adotados na elaboração de um estudo da RedeSist/BNDES (MOUTINHO et al., 2009) sobre o fluxo de comércio de APL do Estado de Pernambuco e da Bahia. O APL selecionado para este trabalho foi o de Fruticultura Irrigada do Vale do Submédio do São Francisco, conforme razões já expostas na introdução. O ano de comparação e referência para a elaboração do Fluxo Comercial Interestadual de Pernambuco e Bahia do APL de Fruticultura Irrigada foi 2006 em função dos dados disponibilizados pelas Secretarias da Fazenda de Pernambuco e da Bahia.

Dada a variedade de frutas cultivadas na região, são consideradas aquelas de maior expressão no comércio interestadual e internacional, bem como os municípios de maior participação nas exportações das respectivas frutas postas na Tabela 1 . Para cada fruta são utilizados os códigos de Classificação Nacional de Atividades Econômicas (CNAE) $)^{8}$ e Nomenclatura Comum do Mercosul (NCM $)^{9}$ para obtenção dos valores das exportações (comércio externo), e Saídas e Entradas (comércio interno), desses produtos nas economias de Pernambuco e da Bahia. O código do IBGE é utilizado para localização dos referidos municípios na composição dos dados sobre produção.

8 Mais informações disponíveis em: < http://www.cnae.ibge.gov.br/>

9 Mais informações disponíveis em: <http://www.mdic.gov.br/sitio/interna/interna.php?area=5\&menu $=1095>$ 
Tabela 1. Cruzamento de CNAEs, NCMs, Estados e Municípios no APL de Fruticultura Irrigada do Vale do Submédio do São Francisco

\begin{tabular}{|c|c|c|c|c|}
\hline NCM & CNAE & Produto & Estado/Município & $\begin{array}{c}\text { Código } \\
\text { IBGE }\end{array}$ \\
\hline $\begin{array}{l}0807.19 .00 \\
0806.10 .00\end{array}$ & $\begin{array}{l}0119907 \\
0132600\end{array}$ & $\begin{array}{l}\text { Melão } \\
\text { Uva }\end{array}$ & $\begin{array}{l}\text { Pernambuco } \\
\text { Petrolina } \\
\text { Lagoa Grande } \\
\text { Santa Maria da Boa Vista } \\
\text { Orocó }\end{array}$ & $\begin{array}{l}2611101 \\
2608750 \\
2612604 \\
2609808\end{array}$ \\
\hline 0801.19 .00 & $\begin{array}{l}0133405 \\
0133410\end{array}$ & $\begin{array}{l}\text { Coco-da-baía } \\
\text { Manga }\end{array}$ & $\begin{array}{l}\text { Bahia } \\
\text { Casa Nova } \\
\text { Sento Sé } \\
\text { Juazeiro } \\
\text { Curaçá }\end{array}$ & $\begin{array}{l}2907202 \\
2930204 \\
2918407 \\
2909901\end{array}$ \\
\hline
\end{tabular}

Fonte: Elaboração própria.

As instituições, fontes, dados secundários e a aplicação dessas informações para a elaboração do Fluxo Comercial e outras análises comparativas são apresentados no Quadro 1. Os dados do fluxo de comércio inter-regional de Pernambuco e Bahia são de 2006. Por problemas de alterações nos sistemas computacionais das duas secretarias apenas o ano de 2006 permitia a compatibilização dos fluxos. Além disso, a partir de 2007 algumas desagregações necessárias não estavam mais disponíveis. É importante considerar também que a coleta de dados fez parte de uma pesquisa mais ampla, "Análise do Mapeamento e das Políticas para APLs no Brasil", realizada pela RedeSist e financiada pelo BNDES com a participação da maioria dos Estados brasileiros, onde o ano de 2006 foi o ponto de corte escolhido pelas possibilidades de compatibilização das bases de dados. Supondo que os fluxos comerciais entre os Estados e Regiões sejam estáveis, por representarem características estruturais da economia nacional, restringir o estudo a este período não implica em prejuízo da análise ${ }^{10}$.

Contudo, os dados para os fluxos comerciais internacionais apresentam maior variabilidade nos preços e volume comercializado, consequentemente foram considerados períodos a partir de 1990, período onde essas séries históricas

$\overline{10}$ A análise de fluxos comerciais entre países muitas vezes é fortemente influenciada por questões cambiais e/ou restrições às transações correntes. Contudo, fluxos comerciais dentro de um mesmo país não sofrem interferência do câmbio. 
estão disponíveis, e também quando as frutas analisadas iniciam sua expansão nas exportações; ou seja, o período relevante para a análise da evolução histórica da formação econômica da fruticultura, especialmente sobre o VSMSF.

Quadro 1. Relação de fontes de dados secundários e sua aplicação na pesquisa

\begin{tabular}{|c|c|c|c|c|}
\hline Instituição & Fontes & Dados & Aplicação & Período \\
\hline $\begin{array}{l}\text { IBGE - Instituto } \\
\text { Brasileiro de } \\
\text { Geografia e } \\
\text { Estatística }\end{array}$ & $\begin{array}{l}\text { Produção } \\
\text { Agrícola } \\
\text { Municipal } \\
\text { (PAM) e Censo } \\
\text { Agropecuário }\end{array}$ & $\begin{array}{l}\text { Área Plantada } \\
\text { em hectares } \\
\text { (ha) e } \\
\text { Quantidade } \\
\text { Produzida em } \\
\text { toneladas (t) }\end{array}$ & $\begin{array}{l}\text { Encontrar o } \\
\text { peso (\%) do APL } \\
\text { na produção da } \\
\text { variedade de } \\
\text { frutas do Estado }\end{array}$ & 1990 a 2010 \\
\hline $\begin{array}{l}\text { MDIC/SECEX } \\
\text { - Ministério do } \\
\text { Desenvolvimento, } \\
\text { Indústria e } \\
\text { Comércio } \\
\text { Exterior/Secretaria } \\
\text { de Comércio } \\
\text { Exterior }\end{array}$ & $\begin{array}{l}\text { Sistema e } \\
\text { Análise das } \\
\text { Informações } \\
\text { de Comércio } \\
\text { Exterior (ALICE- } \\
\text { Web) }\end{array}$ & $\begin{array}{l}\text { Exportações e } \\
\text { Importações de } \\
\text { Pernambuco } \\
\text { e Bahia para o } \\
\text { Exterior }\end{array}$ & $\begin{array}{l}\text { Elaboração } \\
\text { do Fluxo de } \\
\text { Comércio } \\
\text { Internacional de } \\
\text { Pernambuco e } \\
\text { do APL do Vale } \\
\text { do São Francisco }\end{array}$ & 1990 a 2010 \\
\hline $\begin{array}{l}\text { FAO - } \\
\text { Organização das } \\
\text { Nações Unidas } \\
\text { para a Agricultura } \\
\text { e Alimentação }\end{array}$ & FAOSTAT & $\begin{array}{l}\text { Produção, } \\
\text { Exportações e } \\
\text { Importações } \\
\text { Internacionais }\end{array}$ & $\begin{array}{l}\text { Elaboração do } \\
\text { Fluxo Comercial } \\
\text { Internacional } \\
\text { das frutas } \\
\text { analisadas no } \\
\text { estudo }\end{array}$ & $\begin{array}{l}\text { Produção } \\
(1990 \text { a } \\
2010) \\
\text { Exportação e } \\
\text { Importação } \\
(1990 \quad \text { a } \\
2010)\end{array}$ \\
\hline $\begin{array}{l}\text { SEFAZ-PE/BA } \\
\text { - Secretarias } \\
\text { da Fazenda de } \\
\text { Pernambuco e } \\
\text { Bahia }\end{array}$ & $\begin{array}{l}\text { Classificação } \\
\text { Nacional de } \\
\text { Atividades } \\
\text { Econômicas } \\
\text { (CNAE) }\end{array}$ & $\begin{array}{l}\text { Saídas e } \\
\text { Entradas Inter- } \\
\text { regionais }\end{array}$ & $\begin{array}{l}\text { Elaboração } \\
\text { do Fluxo de } \\
\text { Comércio Inter- } \\
\text { regional de } \\
\text { Pernambuco } \\
\text { e da Bahia - } \\
\text { Sertão de São } \\
\text { Francisco }\end{array}$ & 2006 \\
\hline
\end{tabular}

Fonte: Elaboração própria.

Para investigar as informações expostas nesta seção, o referido Fluxo Comercial é estudado em duas partes (ver Quadro 2). A primeira parte buscará verificar se as frutas selecionadas para este estudo têm sua concentração produtiva no 
APL estudado, mostrando que o Sertão de São Francisco pode ser considerado como o principal responsável por exportar essa variedade de frutas no Estado, validando então a condição de que as exportações desses produtos são provenientes desse APL. $\mathrm{Na}$ segunda parte, montam-se os fluxos comerciais do APL de Fruticultura Irrigada com os dados disponíveis do Sistema ALICE-Web para o comércio internacional (Exportações), e das Secretarias da Fazenda de Pernambuco e Bahia para o comércio interestadual (Entradas e Saídas). Abaixo segue uma descrição desses procedimentos com maior detalhamento.

Quadro 2. Etapas do estudo para coleta e aplicação da pesquisa

\begin{tabular}{|l|l|}
\hline \multicolumn{1}{|c|}{ Primeira Parte } & \multicolumn{1}{c|}{ Segunda Parte } \\
\hline $\begin{array}{l}\text { 1 - Encontrar a Área Plantada e a Quantidade } \\
\text { Produzida de cada fruta para Pernambuco e } \\
\begin{array}{l}\text { Bahia e os municípios selecionados do Vale do } \\
\text { Submédio do São Francisco. }\end{array}\end{array}$ & $\begin{array}{l}\text { 3-Encontrar o total de Exportações (comércio } \\
\text { internacional) e das Saídas e Entradas } \\
\text { (comércio interestadual) de cada variedade de } \\
\text { fruta. }\end{array}$ \\
\hline $\begin{array}{l}\text { 2 - Encontrar o peso (\%) do APL para Área } \\
\text { Cultivada e Quantidade Produzida de cada fruta } \\
\text { do Vale do Submédio do São Francisco. }\end{array}$ & $\begin{array}{l}\text { 4 - Aplicar o Peso ao Total da Exportação de } \\
\text { cada variedade de fruta do APL. Em seguida } \\
\text { montar o Fluxo Comercial deste APL. }\end{array}$ \\
\hline
\end{tabular}

Fonte: Elaboração própria.

Portanto, para compreender e analisar a dinâmica desses fluxos internos e externos das mercadorias do APL de Fruticultura Irrigada do Vale do Submédio do São Francisco, a seção que apresenta resultados analisou a balança comercial brasileira e dos Estados da Bahia e de Pernambuco. Em seguida verificou-se a participação do APL na produção e área cultivada de Manga, Uva, Coco-da-baía e Melão desses dois Estados. Provido dessas informações e do arcabouço teórico-metodológico deste estudo se analisou o fluxo comercial internacional de Pernambuco e Bahia e o fluxo comercial interestadual do Vale do Submédio do São Francisco das frutas selecionadas.

\subsection{MODELO DE ANÁLISE}

O modelo de análise (Figura 1) inicia a partir dos mercados e dos ambientes nos quais estão inseridos os APL. Essa contextualização externa permite verificar as relações nas quais estão envolvidas as empresas e instituições do Arranjo. Por 
sua vez, em uma perspectiva socioeconômica de traços históricos singulares, o APL conjuga-se de conceitos e características próprias, tais como: desenvolvimento local; inovação, conhecimento e aprendizagem; ambiente institucional; competitividade e cooperação; e formação sistêmica - que estão intrinsecamente coligados aos mercados e ambientes externos e internos da aglomeração produtiva. Devido a esses aspectos conceituais serem particulares e relacionados tanto ao ambiente externo como ao interno, pode haver entraves e gargalos que dificultam o desenvolvimento do território e dos empreendimentos. Para buscar superar esses problemas e atingir o equilíbrio desejado, promovem-se políticas e ações - realizadas por instituições públicas e privadas. Necessitam-se, contudo, de instrumentos que possam identificar quais são esses entraves para o desenvolvimento do território. O Fluxo Comercial pode ser analisado através do mercado e do comércio identificando aquilo que é obstáculo, e que, portanto, poderá subsidiar a instrução de novas políticas para o APL.

Desse modo, o modelo abaixo apresenta o APL como instrumento de promoção e análise de desenvolvimento local das políticas e seus Fluxos Comerciais como instrumento de análise do desenvolvimento local.

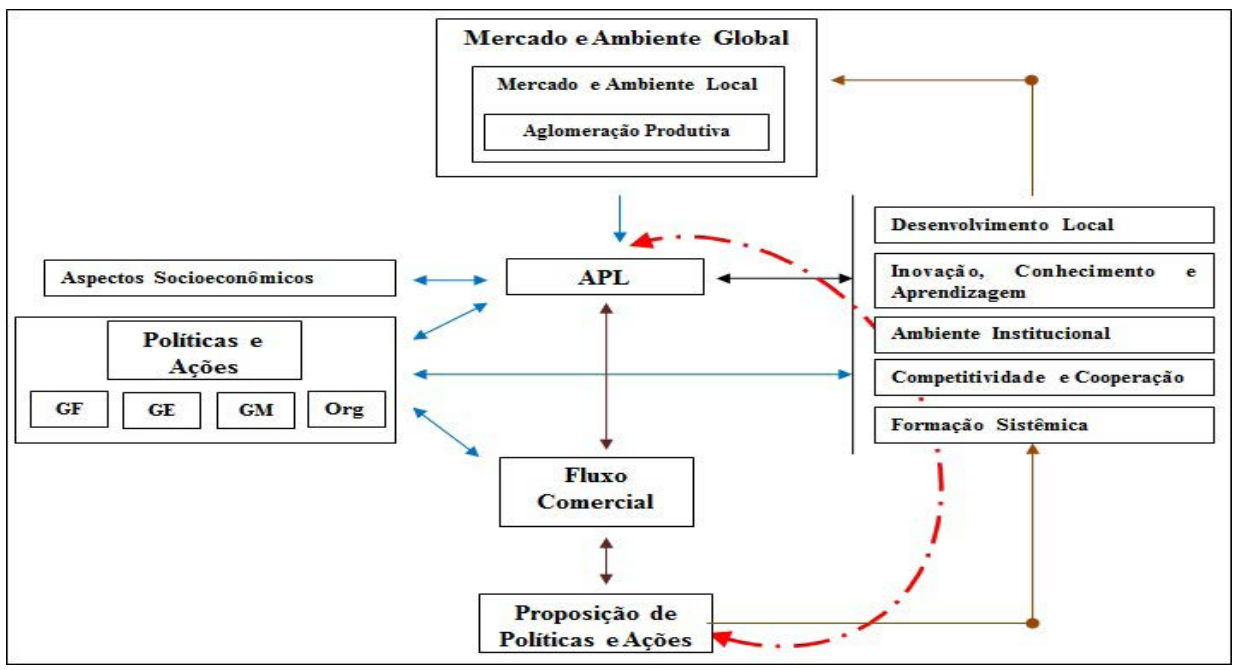

Figura 1. Modelo de Análise

Fonte: elaborado pelo autor com base em Vital (2009).

OBS.: Arranjo Produtivo Local (APL) de Fruticultura Irrigada do Vale do Submédio do São Francisco; Governo Federal (GF), Governo Estadual (GE), Governos Municipais (GM) e Organizações Sociais,

Redes, Fóruns e ONGs (Orgs.). 
A Figura 1 inicia mostrando que os mercados global e local estão relacionados às aglomerações produtivas, e as mudanças nesses mercados refletem no desempenho e nas estratégias das empresas e demais atores do APL. Por sua vez, o Arranjo Produtivo Local convenciona-se às mudanças dos aspectos socioeconômicos do território. Para alcançar essas mudanças, os atores do APL articulam-se com as instituições públicas - das esferas federal, estadual e municipal - e demais organizações, bem como às redes sociais para promover políticas e ações concernentes aos conceitos e características do APL. Desse modo, essas políticas podem promover mudanças nos fluxos comerciais internos (locais e interestaduais) e externos, que podem ser uma supressão de uma barreira não tarifária ou mesmo a divulgação dos produtos em outros mercados. Como os mercados estão sujeitos a oscilações frequentes, entende-se que é preciso identificar, estudar e propor novas políticas para o APL que tenham relação com os conceitos e características deste.

\section{ANÁLISE DOS RESULTADOS}

O APL da Fruticultura Irrigada da região estudada responde anualmente por cerca de $1 / 3$ das exportações de frutas do país, o que lhe confere ser o maior "polo" frutícola de exportação brasileiro. Por esta razão, as oscilações do câmbio e do acirramento da competição no mercado internacional afetam diretamente o desempenho e as estratégias deste APL e o desenvolvimento local do território do VSMSF.

A crise financeira internacional, em 2008-2009, atingiu os investimentos na safra de frutas do VSMSF, pois parte dos recursos são adiamentos de compras feitos pelos principais importadores mundiais, em torno de $\mathrm{R} \$ 300$ milhões anuais (AGECOM/BA, 2009). Com a desaceleração econômica, as trandings dos países europeus (Inglaterra, Alemanha, Holanda, entre outros) e dos Estados Unidos da América suspenderam esses adiamentos, comprometendo os produtoresexportadores do Vale, que se endividaram, e por consequência gerou quedas na produção e exportação.

Esse cenário de crise externa mostra que, embora o VSMSF tenha papel importante na balança comercial brasileira, ainda assim, sua relação comercial é de 
dependência, pois a produção e exportação se concentram em duas variedades de frutas, e que qualquer crise, gargalo ou queda do fluxo comercial afeta todos os atores envolvidos neste APL. Contudo, cabe aos mesmos enxergarem como oportunidade para buscar inovações na melhoria do produto, para garantir capacidade competitiva ou criar oportunidades de novos fluxos que diminuam essa dependência externa, mas a principal reflexão deve estar em uma pauta que discuta a diversificação e dinamização econômica do território.

As frutas mais exportadas do VSMSF são manga e uva, e a participação de ambas na Balança Comercial de Pernambuco e Bahia tem um papel importante. A uva e a manga em Pernambuco são o $4^{\circ}$ e $5^{\circ}$ produtos mais exportados, respectivamente. $\mathrm{Na}$ Bahia, essa posição muda respectivamente para $31^{\circ}$ e $26^{\circ}$ (SECEX/MDIC, 2009). Segundo dados do SECEX/MDIC (2009), essas frutas tiveram grandes quedas nas exportações de 2008 para 2009, diminuindo suas participações na Balança Comercial dos respectivos Estados. A manga teve uma queda de $23 \%$, enquanto que a uva caiu mais de 33\%. A descapitalização foi a principal responsável por essas quedas. Em razão disso, os Governos de ambos os Estados prontamente articularam reuniões com os principais bancos financiadores (Banco do Brasil, Banco do Nordeste do Brasil e Banco Nacional de Desenvolvimento Econômico e Social) para renegociar e postergar dívidas dos contratos vencidos, além de prover aporte de crédito especial para os fruticultores afetados pela crise ${ }^{11}$.

Os registros dos volumes de capitais despendidos para os fruticultores financiarem suas atividades não são facilmente captados. Essa informação não existe nas bases de dados de órgãos oficiais como o Banco Central do Brasil/BCB, porém os fluxos comerciais, que podem ser considerados um reflexo do fluxo de capitais, estão disponíveis em duas bases de dados: i) ALICE-Web, que registra as exportações e importações de mercadorias em valores de free on board (FOB) do Brasil e de suas Unidades Federativas com o Exterior (transações internacionais); e ii) Secretarias da Fazenda da Bahia e Pernambuco, que captam as vendas de bens a partir da Classificação Nacional de Atividades Econômicas (CNAE) entre os Estados (transações interestaduais). Como são duas categorias de informações comerciais

\footnotetext{
$\overline{11}$ O aporte de crédito foi possível a partir da Lei no 11.775 , de 17/09/2008, e da Resolução no 3.899 do Conselho Monetário Nacional, além da Lei $n^{0} 12.249$, para os beneficiários do Programa Nacional de Fortalecimento da Agricultura Familiar.
} 
com registros distintos, inclusive em valores de moeda (ALICE-Web dispõe dos dados em Dólares e a SEFAZ em Reais), suas informações são apresentadas em seções separadas, no entanto as análises dessas informações estão correlacionadas.

\subsection{PARTICIPAÇÃO DO APL NA PRODUÇÃO E ÁREA CULTIVADA DE MANGA, UVA, COCO-DA-BAÍA E MELÃO}

A formação institucional e base científica deste APL considera até as condições propícias do clima e do solo. Todavia, os dados estatísticos para mensurar a real participação desta região no quantitativo das exportações possuem limitações. A Secretaria de Comércio Exterior do MDIC, principal instituição que registra essas informações, desdobra os dados até o nível estadual. A desagregação para nível municipal seria importante para verificar e discutir a capacidade de um APL influir na Balança Comercial dos Estados ou mesmo sobre a atração de investimentos, mas principalmente na capacidade de influenciar no desenvolvimento local, porém, como os APL têm entre suas características a convergência de uma atividade econômica em um território estabelecida por convenções históricas e culturais, é possível, portanto, buscar outros dados estatísticos mais desagregados e inferir por intermédio deles qual seria a força econômica do local na dinâmica produtiva e comercial de uma região ou mesmo de um APL. Mesmo analisando o APL de Fruticultura Irrigada com dados dos oito municípios dos dois Estados, ainda assim não houve dificuldades de somá-los e considerá-los em conjunto, em parte pelo nível de detalhes que o IBGE disponibiliza sobre a produção de cada município e, por outra, porque a literatura sobre o tema estuda os municípios deste APL como agregados em um território distinto, com dinâmicas e ações próprias, especialmente por suas relações com as cadeias produtivas nacionais e internacionais.

Anualmente o IBGE publica dados sobre Produção Agrícola Municipal/ PAM, entre os quais a respeito de Área Plantada e Quantidade Produzida. Com essas duas dimensões foi possível averiguar a participação do APL na produção de manga, uva, coco-da-baía e melão nos Estados da Bahia e Pernambuco, e com os pesos percentuais obtidos se teve um resultado aproximado que serviu como critério de análise para considerar o APL como exportador destas variedades. 
As quatro frutas selecionadas somam 38 mil hectares ou 31,6\% da área irrigada utilizada atualmente, sendo que $87 \%$ dessa área estão ocupados por manga e uva. Os municípios de Petrolina e Juazeiro respondem por grande parte da área disponível (76,35\%) e quantidade produzida (76,86\%) (IBGE/PAM, 2008).

Somadas as áreas plantadas e quantidades produzidas dos Estados e dos Municípios do APL são encontrados os resultados apresentados na Tabela 2. A manga possui um peso maior do que 50\% para área plantada e aproximadamente $70 \%$ da quantidade produzida, mas considerando que as variedades exportadas são produzidas principalmente no Vale do Submédio do São Francisco, como a Tommy Atkins, Haden, Keitt, Kent e Palmer. A variedade Tommy Atkins abrange de 83\% a 97,1\% das áreas de cultivo dos principais perímetros irrigados - Mandacaru, Torreão, Maniçoba, Tourão, Curaçá e Bebedouro (FAVERO, 2008). Como a manga é produzida em diferentes regiões de ambos os Estados, inclusive variedades viáveis apenas para industrialização ou venda em Centrais de Abastecimento e Feiras Livres, como a Rosa e Espada, e por ser uma fruta tropical bastante comum na culinária e mesa das famílias brasileiras, esta seria uma razão para compreender o motivo de aproximadamente $46 \%$ serem produzidas fora do APL.

Tabela 2. Peso (\%) da Área Plantada e Quantidade Produzida de Manga, Uva, Coco-da-baía e Melão no APL de Fruticultura Irrigada do Vale do Submédio do São Francisco em relação às áreas plantadas e quantidades produzidas somadas da Bahia e Pernambuco, 2010

\begin{tabular}{lcccc}
\hline Fruta & Área Plantada (ha) & $\%$ & $\begin{array}{c}\text { Quantidade } \\
\text { Produzida }\end{array}$ & $\%$ \\
\hline Manga (t) & 20.964 & 53,5 & 432.353 & 61,4 \\
Uva (t) & 9.587 & 93,6 & 265.057 & 96,9 \\
$\begin{array}{l}\text { Coco-da-baía (mil } \\
\text { frutos) }\end{array}$ & 3.885 & 4,4 & 85.360 & 14,9 \\
Melão (t) & 1.417 & 55,5 & 27.725 & 54,1 \\
\hline
\end{tabular}

Fonte: elaborada a partir de dados do IBGE - Pesquisa Agrícola Municipal, 2010.

Em relação à uva, que tem índices próximos de 100\%, é uma fruta de clima temperado, adaptada à produção na região semiárida. As primeiras experiências para sua inserção foram iniciadas já nos anos 1960. Porém, somente no início dos 
anos 1990 é que pesquisas foram realizadas pela Empresa Brasileira de Pesquisa Agropecuária/ Centro de Pesquisa Agropecuária do Trópico Semiárido (Embrapa/ CPATSA), Instituto de Tecnologia de Pernambuco (ITEP), Associação dos Exportadores de Hortigranjeiros e Derivados do Vale do São Francisco (VALEXPORT) e Sebrae, a fim de desenvolver uma variedade apirênica (sem semente), que posteriormente foi introduzida comercialmente no início do século XXI (TAVARES; LIMA, 2009). Outras regiões produzem uva, como São Vicente Férrer e Macaparana, em Pernambuco, com aproximadamente 500 ha plantados em $2009^{12}$, contudo, o plantio é direcionado para produção de uvas in natura, suco concentrado e vinhos para o comércio regional.

As variedades produzidas no semiárido do Vale do São Francisco são destinadas para mesa e produção de vinhos. Como não é possível desagregar os dois tipos de uva, a variedade sem semente (mesa) ou para industrialização, é assumido que aquelas que são exportadas são do primeiro tipo, enquanto que as comercializadas internamente, principalmente nos Estados da Bahia e Pernambuco, são destinadas à produção de vinhos finos, sucos de uva concentrados e outros derivados.

O coco-da-baía tem os índices mais baixos, o que dificulta deduzir se o APLé o principal responsável pelas exportações. Pois, além disso, a maioria dos produtores é de pequeno porte, menos capitalizados e que direcionam para indústria de água de coco e outros derivados, presentes na região. Afora que o custo de transporte é mais elevado, pois o coco-da-baía tem um peso que varia de 1,5 a 2,0 $\mathrm{Kg}$, e apenas $20 \%$ é referente ao volume de água. No entanto, o que poderia constatar que essas exportações registradas pela SECEX/MDIC sejam do APL seria a presença da entidade Grupo de Coco do Vale do São Francisco (GCV), criado em 1999 com o objetivo de organizar os produtores da região na comercialização interna e externa, mas essa entidade não existe mais. O Grupo de Coco do Vale do São Francisco era apoiado pela VALEXPORT, que auxiliou na prospecção de destinos internacionais como Inglaterra e Itália (SECEX/MDIC, 2010). O Sebrae e a Embrapa também apoiaram este Grupo no planejamento da viabilidade econômica do escoamento de sua produção para

\footnotetext{
$\overline{12}$ Aproximadamente $95 \%$ da área cultivada estão no município de São Vicente Férrer, que plantou as primeiras videiras desde 1944. Atualmente tem intensificado na industrialização de sucos concentrados e vinhos finos. Também está desenvolvendo variedades sem semente (TAVARES; LIMA, 2009).
} 
o exterior. Contudo, a exportação de coco não é fácil, pelas razões apresentadas acima, o que acarreta em uma quantidade incipiente e desregular de exportações; nos últimos seis anos não houve nenhuma ocorrência saindo de Pernambuco e da Bahia (SECEX/MDIC, 2010).

O melão está inserido na produção dos perímetros irrigados há mais tempo que a uva e a manga, inclusive o Vale era reconhecido pela produção desta fruta, porém, segundo Silva (2001), a produção diminuiu no final dos anos 1980 devido a uma experiência mal sucedida de exportação que trouxe prejuízos para o Vale, tanto financeiros quanto de imagem. O motivo foi a variedade de tipos de melão produzidos pelos pequenos agricultores, com tamanhos, sabores e qualidade diferentes, o que acarretou em baixos preços pagos nos leilões em Rotterdam, que não eram sequer suficientes para fazer face aos custos de exportação, levando muitos produtores a abandonarem o cultivo. Contudo, após o sucesso da produção de outras frutas na região e o êxito da produção de melão no Polo Açú/Mossoró, a produção voltou a crescer, principalmente entre os pequenos produtores, agora mais experientes e com melhor orientação para exportar seus produtos (LIMA; CAMPOS, 2005).

A participação do melão do VSMSF em relação ao total da área cultivada e quantidade produzida de Pernambuco e Bahia, que era de $86 \%$ e $85 \%$, respectivamente, em 2006, diminuiu em 2010 para 55,5\% e 54,1\%. Os valores sugerem que as exportações de melão sejam provenientes, em quase sua totalidade, deste APL, pois além da produção ser maior, o território compreende um aglomerado institucional que favorece a organização e prospecção de mercados externos. Além disso, a proximidade com a Embrapa/CPATSA facilita o desenvolvimento de novas variedades que atendam ao mercado consumidor externo (IBGE/PAM, 2008).

\subsection{FLUXO COMERCIAL INTERNACIONAL DO APL}

As quatro variedades de frutas analisadas na seção anterior tiveram resultados diferentes dos seus pesos em relação à produção somada dos Estados da Bahia e Pernambuco, todavia, compõe o APL uma base institucional comum e fortalecida, ou seja, a formação do capital social no território proveu os subsídios para que os produtores e atores desenvolvessem relações cooperativas que facilitaram 
ao APL difundir o conhecimento tácito, científico e inovativo. Nesse âmbito, a institucionalidade é um elemento-chave do sistema produtivo local no tocante à participação nas exportações de frutas.

A Balança Comercial dos Estados e do Brasil mostra que há inflexões e outros movimentos implícitos que podem alterar o comportamento da economia nacional ou regional, inclusive nos territórios em que haja especialização de uma atividade econômica integrada a uma cadeia internacional de comércio, como é a de fruticultura irrigada, que tem seus contratos estabelecidos em Dólares ou Euros.

Cada fruta representa um fluxo de comércio com nuances e outros aspectos peculiares concernentes ao determinado pelo público demandante. Há, entretanto, crises e entraves que podem afetar a produção ou comercialização dessas frutas igualmente. Portanto, considerou-se que as exportações da uva, manga e melão que saem dos Estados da Bahia e de Pernambuco sejam provenientes do APL, um território sistêmico.

Como as informações do Coco-da-baía são incipientes e não há uma base institucional organizada atualmente para essas exportações, além do que a $\operatorname{AMACOCO}^{13}$ e o mercado interno têm absorvido grandes quantidades que são produzidas no Vale, portanto, não é possível considerar que as exportações realizadas são oriundas desse APL. Mesmo sabendo que há "experiências" de exportações realizadas por alguns núcleos dos perímetros irrigados, mas que ainda não foram compensatórias, logo o fornecimento para a indústria local e mercado interno ainda são as prioridades. Porém, recentemente a multinacional PepsiCo comprou a produtora nacional AMACOCO, das marcas Kero Coco e Trop Coco, com fábricas em Petrolina (PE) e São Mateus (ES). O coco utilizado nessa agroindústria é proveniente de fornecedores da Bahia e Pernambuco, sendo que 65\% procedem diretamente de Petrolina e Juazeiro (SOUZA et al., 2009). Grande parte do consumo da água de coco envasilhada segue para o Centro-Sul do país, por meio das redes de varejo, e a outra parte segue para o exterior, tendo como principais destinos: Inglaterra, Alemanha, Estados Unidos da América, Japão e Angola. O coco também é uma importante matéria-prima para outras agroindústrias nacionais com produtos para culinária (leite de coco, coco ralado, óleo, molhos, etc), o que confirma a

\footnotetext{
13 Empresa brasileira produtora de água de coco, com sede no município de Petrolina (PE).
} 
tendência de que a venda desse produto é uma alternativa com maior viabilidade técnica e econômica do que in natura (ibidem). A uva e a manga são as culturas com movimentos mais ascendentes. O início da produção voltada para exportação remonta ao final dos anos 1980, mas a partir de um cenário cambial propício na segunda metade dos 1990, decorrente de uma estabilidade promovida pela política macroeconômica brasileira para controle da inflação e ajuste do câmbio, as frutas de regióes como o Vale do São Francisco adquiriram espaço no mercado externo, favorecidos também pelas condições edafoclimáticas e aumento do consumo de frutas, principalmente exóticas e de contraestação (TAVARES; LIMA, 2009; FAVERO, 2008). Nem todas as frutas, porém, mantiveram a ascensão dos primeiros anos da abertura comercial, como é o caso da uva, que teve fracos resultados entre 1996 e 1999, por causa de obstáculos como as exigências dos consumidores europeus, que preferem uvas apirênicas. A partir de 2000 e 2001 quando as primeiras variedades sem semente foram comercializadas, as exportações cresceram 131\%. A introdução da uva sem semente foi fundamental, atualmente se estima que mais de $60 \%$ da produção seja desse cultivo (SECTI-BA, 2008). Em 2000, foram exportados US\$ 12 milhões e, em 2008, foram US\$ 170 milhões, o crescimento foi praticamente exponencial. A fase de ascensão da uva teve uma queda entre 2008 e 2009 por causa da crise internacional que restringiu o crédito e a renda dos consumidores. $\mathrm{O}$ ano de 2010 tem apresentando um leve crescimento em relação ao ano anterior, o que demonstra que a crise não se alongou (SECEX/MDIC, 2010).

Os principais destinos da uva do VSMSF são a União Europeia $(74,2 \%)$, Estados Unidos da América (21,6\%), Canadá (1,15\%) e países do Mercosul (0,77\%). Na Europa, a Holanda, além de ser o maior importador europeu com 43\%, é também o principal redistribuidor, o que lhe confere uma importância estratégica para o Vale na obtenção de novos mercados consumidores dentro da Europa (SECEX/MDIC, 2010). Os Emirados Árabes Unidos, no Oriente Médio, importam menos de 0,5\% (US\$155 mil) das uvas do Vale do São Francisco, mas é um mercado promissor, pois, anualmente importam mais de US\$ 45 milhões desse produto (SECEX/MDIC, 2010; FAOSTAT, 2010).

A manga ganhou uma maior projeção ainda nos anos 1990, pois as ações da VALEXPORT com o programa de controle da mosca da fruta tiveram efeito imediato, 
com isso o Vale do São Francisco alcançou também o mercado estadunidense que representa hoje 16\% das vendas (SECEX/MDIC, 2010). Favero (2008) também destaca que a reestruturação produtiva aplicada no APL na segunda metade da década de 1990 resultou em uma maior interação e estabelecimento de parcerias entre pequenos produtores e as empresas exportadoras que foi importante para aumentar o volume e manter a regularidade da comercialização.

Até 2003, a receita da comercialização da manga para o exterior superava a de uva, ainda assim a produção e exportação continuam em expansão, mas com alguns momentos de queda, como ocorreu em 2004 em razão das chuvas intensas e nos períodos de crise na conjuntura econômica internacional ou de mudanças na política cambial brasileira. Além disso, segundo Favero (2008) 63,6\% das mangas vendidas pelo Brasil no exterior é por consignação, o que a torna vulnerável a quaisquer mudanças no mercado, tal como ocorreu em 2008 e 2009, que diminui as exportações em mais de US\$20 milhões, um valor expressivo para uma região que tem na fruticultura irrigada a principal atividade econômica indutora de desenvolvimento socioeconômico.

O escoamento de manga do Vale também se concentra na Europa $(74,3 \%)$, Estados Unidos da América (19,8\%), Canadá (2,7\%) e América Latina (0,95\%). A Holanda converge $50,1 \%$ do comércio e como visto anteriormente é o principal responsável por abastecer países europeus, particularmente do Leste (SECEX/MDIC, 2010). No mercado asiático, o Japão aparece como outro destino propício: importa mais de US\$ 1,5 milhões do Vale do São Francisco. Atualmente o Japão compra aproximadamente US\$47 milhões em manga, principalmente do México, Filipinas e Tailândia (SECEX/MDIC, 2010; FAOSTAT, 2010).

O melão tem uma importância menor na demanda de produtos do Vale frente ao expressivo sucesso da manga e da uva, mas vem ganhando espaço em razão desse aumento da demanda. Essa ascensão ainda tem sido pequena, pois grande parte da produção e das exportações dessa fruta é procedente do Rio Grande do Norte, especificamente do Polo Baraúna/Açú/Mossoró. O melão é a segunda fruta mais exportada em valores de US\$ no Brasil, um aspecto que favorece a possibilidade de expansão de sua produção no Vale do São Francisco. Contudo, além da concorrência com o referido polo do Rio Grande do Norte, e também com o Baixo Jaguaribe no 
Ceará, outro entrave que poderá estagnar as exportações dessa fruta no Vale referese à variedade que produz, Yellow Honey Dew/YHD, por seu baixo teor de sólidos solúveis, menos apreciada em alguns grandes mercados consumidores (LIMA; CAMPOS, 2005). A pesquisa por novas variedades é imprescindível para manutenção do crescimento e também para ganhar destaque nesse competitivo mercado. Ainda assim, essa variedade é a mais viável economicamente, pois suporta até trinta dias depois da colheita, uma capacidade superior a outras variedades, desse modo mais adequada à exportação.

As exportações de melão do Vale se mantiveram em um patamar abaixo de US\$ 1 milhão até 2008, porém, em 2009, o valor aumentou: em 2010 já havia passado de US\$ 1,6 milhões. Esse movimento de crescimento entre 2008 e 2009 foi o inverso daquele percebido na manga e uva que sofreram uma queda nesse período. Uma possível explicação é a diminuição em $30 \%$ das exportações de melão procedentes do Polo Baraúna/Açú/Mossoró, que com essa perda abriu espaço para o Vale do Submédio do São Francisco (IBGE/PAM, 2009; SECEX/MDIC, 2010).

O destino comercial do melão do Vale é mais concentrado: $98 \%$ são vendidos para a Europa, sendo a Holanda $(34,1 \%)$ e a Espanha (30\%) seus principais recebedores. Os países da América Central (Guatemala, Costa Rica e Honduras) são os principais fornecedores dos EUA e Canadá, que no total importam mais de US\$ 30 milhões por ano (SECEX/MDIC, 2010; FAOSTAT, 2010).

Tal como no Vale, o Polo Baraúna/Açú/Mossoró tem um forte investimento de empresas privadas aliado aos investimentos públicos, inclusive do INCRA que assentou produtores familiares na microrregião de Mossoró. Nesse Polo, contudo, não há uma instituição que coordene e articule a comercialização, tal como a VALEXPORT no VSMSF. As próprias empresas da região, que por meio de processos verticalizados de produção acessam os principais mercados importadores (FUNCKE et al., 2009). Outra diferença entre os territórios está no foco da produção, enquanto que os produtores do Sertão do Apodi se especializaram na produção do melão (e também da melancia), no Sertão do São Francisco, a produção ocorre no período de entressafra da região de Baraúna/Açú/Mossoró, nos demais meses, os produtores do Vale se dedicam a outras culturas (NACHREINER; BOTEON; PAULA, 2002).

Comparando o desempenho do melão no Vale do Submédio do São Francisco e o Polo Baraúna/Açú/Mossoró percebe-se que a participação nas exportações do 
VSMSF está abaixo de $2 \%$, enquanto que as de Baraúna/Açú/Mossoró conseguem superar o patamar de 70\% e alcançam valores de exportações entre US\$ 45 a 85 milhões. Isto demonstra uma especialização na produção maior do referido Polo do que a observada no Vale (IBGE/PAM, 2010; SECEX/MDIC, 2010).

Entre 2006 e 2009 a quantidade produzida de melão diminuiu no Nordeste, mas suas exportações aumentaram. Neste APL do Vale do Submédio do São Francisco a produção também caiu, mas suas exportações aumentaram. Como é uma fruta menos apreciada no mercado interno, e no externo está em expansão, empresas têm investido mais no plantio direcionado para o mercado europeu e estadunidense.

\subsection{FLUXO COMERCIAL INTERESTADUAL DO APL DE FRUTICULTURA}

Importantes redes varejistas aproveitam as vantagens e externalidades positivas da região para criar uma produção verticalizada para atender a demanda que se amplia por produtos saudáveis e naturais no país, especialmente de consumidores do Sul e Sudeste. Aproximadamente 26\% das mangas, 32\% das uvas e 7,5\% dos melões produzidos no Vale são exportados, o que garante ao comércio interno a importância de escoar ou utilizá-la na indústria a maior parte da produção não destinada ao mercado externo (SECEX/MDIC, 2010; IBGE, 2010).

Os dados fornecidos pelas Secretarias da Fazenda de Pernambuco e Bahia do ano de 2006 mostram o fluxo de saídas e entradas das frutas analisadas nesse estudo. As informações recebidas para Pernambuco foram filtradas compreendendo apenas os municípios de Petrolina, Santa Maria da Boa Vista, Lagoa Grande e Orocó, e para Bahia foram os municípios de Juazeiro, Casa Nova, Curaçá e Sento Sé. O Estado da Bahia possui outros polos frutícolas importantes como Livramento de Nossa Senhora na Bacia do Rio de Contas, região Sudoeste, que produz manga da variedade Tommy Atkins. Contudo, foram somente considerados os valores dos municípios componentes do APL e que possuem um peso relevante nos fluxos interno e externo do Vale do Submédio do São Francisco, portanto, todas as saídas e entradas são pertencentes ao APL. 
A Tabela $3^{14}$ apresenta os dados somados das saídas e entradas das quatro frutas estudadas de Pernambuco e Bahia com outros Estados e regiões brasileiras. Essas informações mostram que mesmo o volume do comércio interestadual sendo maior, os valores são menores do que nas exportações no mesmo período, enquanto que as saídas registraram R\$34 milhões, as exportações foram de US\$ 196 milhões ou R\$ 428 milhões (SECEX/MDIC, 2006) ${ }^{15}$. Contudo, a partir dessa comparação é plausível o entendimento de que o APL é dependente do mercado externo e de suas variações.

Tabela 3. Fluxo Interestadual da Fruticultura Irrigada do APL do Vale do Submédio do São Francisco (em R\$)

(continua)

\begin{tabular}{cccccc}
\hline UF & Saída & Entrada & Saldo & $\% \mathbf{S}$ & $\% \mathbf{E}$ \\
\hline AC & 0,00 & 0,00 & 0,00 & $0,00 \%$ & $0,00 \%$ \\
AM & $117.750,00$ & 0,00 & $117.750,00$ & $0,35 \%$ & $0,00 \%$ \\
AP & 0,00 & 0,00 & 0,00 & $0,00 \%$ & $0,00 \%$ \\
PA & $771.565,00$ & $34.082,62$ & $737.482,38$ & $2,27 \%$ & $0,13 \%$ \\
RO & $4.200,00$ & 0,00 & $4.200,00$ & $0,01 \%$ & $0,00 \%$ \\
RR & 0,00 & 0,00 & 0,00 & $0,00 \%$ & $0,00 \%$ \\
TO & $36.256,00$ & 0,00 & $36.256,00$ & $0,11 \%$ & $0,00 \%$ \\
\hline NORTE & $929.771,00$ & $34.082,62$ & $895.688,38$ & $2,73 \%$ & $0,13 \%$ \\
\hline AL & $56.266,50$ & $121.902,88$ & $-65.636,38$ & $0,17 \%$ & $0,47 \%$ \\
CE & $1.430 .261,80$ & $1.678 .297,27$ & $-248.035,47$ & $4,21 \%$ & $6,42 \%$ \\
MA & 0,00 & $88.802,14$ & $-88.802,14$ & $0,00 \%$ & $0,34 \%$ \\
PB & $182.828,32$ & $184.611,56$ & $-1.783,24$ & $0,54 \%$ & $0,71 \%$ \\
PI & $49.462,75$ & $22.872,74$ & $26.590,01$ & $0,15 \%$ & $0,09 \%$ \\
RN & $219.962,20$ & $66.345,86$ & $153.616,34$ & $0,65 \%$ & $0,25 \%$ \\
SE & $10.129 .240,90$ & $7.767 .861,98$ & $2.361 .378,92$ & $29,79 \%$ & $29,71 \%$ \\
\hline NORDESTE & $12.068 .022,47$ & $9.930 .694,43$ & $2.137 .328,04$ & $35,49 \%$ & $37,98 \%$ \\
\hline
\end{tabular}

$\overline{14}$ Nessa Tabela não estão os dados do fluxo entre Bahia e Pernambuco, pois essas transações ocorrem no próprio APL. Além do que, o volume de comércio dentro do APL é de R\$22,3 milhões nas entradas e R\$52,2 milhões nas saídas, que se fossem considerados gerariam saldos negativos neste APL.

15 A conversão foi realizada com a cotação média de 2006, que foi de $\mathrm{R} \$ 2,1761$, de acordo com o Departamento Econômico do Banco Central do Brasil 


\begin{tabular}{cccccc}
\hline & & & & & (conclusão) \\
\hline DF & $863.547,59$ & 0,00 & $863.547,59$ & $2,54 \%$ & $0,00 \%$ \\
GO & $238.147,00$ & $9.621,25$ & $228.525,75$ & $0,70 \%$ & $0,04 \%$ \\
MS & 0,00 & 0,00 & 0,00 & $0,00 \%$ & $0,00 \%$ \\
MT & 0,00 & 0,00 & 0,00 & $0,00 \%$ & $0,00 \%$ \\
\hline CENTRO-OESTE & $1.101 .694,59$ & $9.621,25$ & $1.092 .073,34$ & $3,24 \%$ & $0,04 \%$ \\
\hline ES & $687.199,00$ & $323.783,67$ & $363.415,33$ & $2,02 \%$ & $1,24 \%$ \\
MG & $848.555,94$ & $678.203,03$ & $170.352,91$ & $2,50 \%$ & $2,59 \%$ \\
RJ & $7.016 .535,36$ & $325.713,03$ & $6.690 .822,33$ & $20,64 \%$ & $1,25 \%$ \\
SP & $7.765 .219,82$ & $8.777 .192,54$ & $-1.011 .972,72$ & $22,84 \%$ & $33,57 \%$ \\
\hline SUDESTE & $16.317 .510,12$ & $10.104 .892,27$ & $6.212 .617,85$ & $47,99 \%$ & $38,65 \%$ \\
\hline PR & $448.737,83$ & $1.670 .164,43$ & $-1.221 .426,60$ & $1,32 \%$ & $6,39 \%$ \\
RS & $2.828 .159,85$ & $2.973 .715,44$ & $-145.555,59$ & $8,32 \%$ & $11,37 \%$ \\
SC & $227.691,29$ & $1.422 .936,58$ & $-1.195 .245,29$ & $0,67 \%$ & $5,44 \%$ \\
\hline SUL & $3.504 .588,97$ & $6.066 .816,45$ & $-2.562 .227,48$ & $10,31 \%$ & $23,20 \%$ \\
\hline EX & $\mathbf{7 8 . 4 6 2 , 8 4}$ & 0,00 & $78.462,84$ & $0,23 \%$ & $0,00 \%$ \\
\hline TOTAL & $\mathbf{3 4 . 0 0 0 . 0 4 9 , 9 9}$ & $\mathbf{2 6 . 1 4 6 . 1 0 7 , 0 2}$ & $\mathbf{7 . 8 5 3 . 9 4 2 , 9 7}$ & $\mathbf{1 0 0 , 0 0 \%}$ & $\mathbf{1 0 0 , 0 0 \%}$ \\
\hline
\end{tabular}

Fonte: Elaboração própria a partir de dados da SEFAZ - BA/PE (2006).

No mercado interno, 35,49\% dessas vendas e 37,98\% das compras são realizadas com os Estados da região Nordeste, sendo a uva e a manga as frutas mais comercializadas; o saldo do Nordeste é positivo em $\mathrm{R} \$ 2,1$ milhões, grande parte em razão das transações com o Sergipe.

Além do Nordeste, o VSMSF é superavitário com as regiões Norte, CentroOeste e Sudeste. Com o Norte e Centro-Oeste os valores não superam R\$ 1,1 milhões. O Sudeste, desconsiderando o fluxo entre Pernambuco e Bahia, é a região que mais compra frutas do Vale, cerca de $\mathrm{R} \$ 16$ milhões, descontadas as entradas, $\mathrm{o}$ saldo fica em $\mathrm{R} \$ 6,2$ milhões. A preferência é pela uva, $\mathrm{R} \$ 11,4$ milhões, mas também são comercializados coco-da-baía ( $\mathrm{R} \$ 2,3$ milhões) e manga (R \$ 2,6 milhões).

Em relação ao coco, $70 \%$ das saídas e $96 \%$ das entradas são oriundas da parte pernambucana do APL, com esses percentuais é possível considerar que as transações interestaduais passam por esta parte do Vale do São Francisco em razão de Petrolina ter uma grande indústria que compra grandes quantidades de coco-dabaía. 
Apesar da grande produção do Vale se destinar à agroindústria local, ainda assim há outras indústrias em São Paulo e também em Sergipe que compram principalmente para o envasamento de água-de-coco.

O saldo com o Sul é negativo em $\mathrm{R} \$ 2,5$ milhões, principalmente por causa da uva, com mais de $\mathrm{R} \$ 5$ milhões comprados e $\mathrm{R} \$ 3$ milhões vendidos. O destino principal são os municípios de Lagoa Grande, Santa Maria da Boa Vista e Petrolina que adquiriam $\mathrm{R} \$ 4,2$ milhões. Sendo este o território do Sistema Produtivo Local de Vitivinicultura, incluindo também Casa Nova, é possível considerar que as uvas e também vinhos provenientes do Sul e Sudeste têm relação com o fato de haver filiais das mesmas nesses municípios, ou mesmo por haver empresas que prestam serviços especializados de comercialização, que se utilizam da base institucional e a indicação geográfica para fomentar os negócios (MOUTINHO et al., 2009).

A Tabela 4 mostra os mesmos resultados totais da tabela anterior, no entanto, os apresenta por fruta. A manga e a uva possuem saldos negativos, principalmente em decorrência das transações realizadas entre Pernambuco e Bahia, que foram aqui desconsideradas por serem transacionadas dentro do próprio APL. O coco-da-baía também tem uma parte transacionada dentro do APL, cerca de R\$232,5 mil, mas como este valor não está sendo considerado nesta tabela, o saldo é positivo: R\$962 mil. A produção de coco no Vale do São Francisco tem uma importância fundamental quanto ao encadeamento com a indústria, principalmente de envasamento de água de coco, bebida que tem alcançado bons preços e concorre com refrigerantes, isotônicos, sucos, etc. Nesse caso, nem todo volume produzido e vendido para a indústria é registrado nesses fluxos, pois assim, o valor seria bem mais alto. Empresas como a AMACOCO têm, além de área própria, uma rede de pequenos produtores que comercializam diretamente com ela. O transporte é da própria indústria que vai até as propriedades buscar os cocos.

Tabela 4. Fluxo Comercial Interno de Melão, Uva, Coco-da-baía e Manga (em R\$)

\begin{tabular}{llrrr}
\hline CNAE & Descrição & \multicolumn{1}{c}{ Saída } & \multicolumn{1}{c}{ Entrada } & \multicolumn{1}{c}{ Saldo } \\
\hline 50119907 & CULTIVO DE MELÃOO & $151.923,10$ & 0,00 & $151.923,10$ \\
50132600 & CULTIVO DE UVA & $25.772 .267,36$ & $15.746 .165,91$ & $10.026 .101,45$ \\
50133405 & CULTIVO DE COCO-DA-BAíA & $3.297 .028,36$ & $2.335 .000,06$ & $962.028,30$ \\
50133410 & CULTIVO DE MANGA & $4.930 .754,27$ & $8.064 .941,05$ & $-3.134 .186,78$ \\
\hline & TOTAL & $34.151 .973,09$ & $26.146 .107,02$ & $8.005 .866,07$ \\
\hline
\end{tabular}

Fonte: Elaboração própria a partir de dados da SEFAZ - BA/PE (2006). 
O comércio do melão registrado nessas tabelas é proveniente somente de Petrolina, não há registros das transações de melão pelos municípios baianos, mesmo sabendo que há comercialização, principalmente exportação por parte dos municípios baianos, mas como a predominância da produção em algumas fazendas são uva e manga, muitos proprietários plantam melão como produto secundário e somente nos meses de entressafra do Polo Baraúna/Açú/Mossoró, por essa situação, as propriedades devem ter sido registradas no CNAE como produtoras de manga ou uva. O valor do melão de $\mathrm{R} \$ 151.923,10$ foi destinado para a Bahia, o que pode configurar que o produto será comercializado no Mercado de Juazeiro, ou que será exportado por alguma empresa baiana e necessitou de uma complementação, ou mesmo alguma empresa sediada na Bahia adquiriu para distribuir nos grandes centros urbanos. Outro município de Pernambuco que comercializa melão para outros Estados é Ibimirim, no Sertão do Moxotó, contudo, não há qualquer registro de produção deste município, o motivo seria que a produção comercializada é proveniente de Floresta, Petrolândia ou Inajá, que são vizinhos a Ibimirim. Foram $\mathrm{R} \$ 562$ mil comercializados, sendo que $80 \%$ foram para o Rio Grande do Norte e o restante para São Paulo (SEFAZ - PE/BA, 2006).

As frutas chegam até o consumidor do Sul e Sudeste ao menos por dois meios, o primeiro é o Mercado do Produtor de Juazeiro que atua como importante distribuidor nacional de produtos agropecuários que são recebidos e vendidos de várias regiões do país. Mas a alternativa que vem tomando importância são as redes de varejo como o Grupo Carrefour e o Bompreço/Walmart, que atentos em responder às demandas dos consumidores passam a exigir também frutas com o mesmo padrão comercializado para o exterior.

$\mathrm{O}$ produto in natura com maior qualidade obtém maiores preços de vendas, mas beneficiar para vender a fruta fatiada e embalada para consumo imediato ou até transformar em matérias-primas para indústrias especializadas de cosméticos e alimentos são formas de agregar valor que têm ganhado importância e poderá ser uma tendência futura, mas desde que sejam realizadas pesquisas para adaptar espécies às condições do semiárido e sejam específicas para indústria, pois as variedades exportadas não são consideradas aptas, principalmente por serem mais caras, o que inviabilizaria qualquer forma de processamento. Para reduzir ainda 
mais os custos, indústrias estrangeiras e nacionais seriam instaladas próximas ao local da produção, como já ocorre com o vinho e a água de coco. A atração desses investimentos beneficiaria diretamente o produtor familiar que tem dificuldades para escoar sua produção, dependendo dos grandes produtores para barganhar seus preços e comercializar.

\section{CONCLUSÕES}

O trabalho estudou as relações do APL de Fruticultura Irrigada do Vale do Submédio do São Francisco com seus fluxos comerciais interestaduais e internacionais a partir de uma visão sistêmica com a finalidade de identificar a força econômica do local nessa dinâmica.

Essa visão sistêmica mostra que o Vale do São Francisco possui um conjunto de características climáticas, produtivas e relações institucionais próprias, que é imprescindível o estímulo à inovação tecnológica, pois não há modelos, fórmulas ou pacotes que atendam a todas as especificidades, por isso a importância da diversidade de instituições que possam elaborar estratégias políticas e ações combinadas com o desenvolvimento local.

No tocante aos fluxos comerciais, as exportações são o principal caminho utilizado pelos produtores e empresas do Vale do Submédio do São Francisco para fomentar o dinamismo da economia local, tanto na atração de fluxos de capitais como também na geração de renda e empregos diretos e indiretos, na atração de mais investimentos públicos e privados e também no desenvolvimento socioeconômico. Porém, as mudanças do mercado externo têm mostrado que o APL é bastante sensível a elas (e porque não, vulnerável), inclusive por provocar endividamento quando ocorrem situações adversas como a valorização das cotações do Real sobre o Dólar ${ }^{16}$, diminuindo o lucro das operações dos produtores, ou quando as trandings passam a importar um volume menor ou pagar um valor abaixo do esperado. Essas oscilações influenciam principalmente nos contratos dos empregos, que cada vez

$\overline{16}$ Entre 2006 e 2008 , cuja taxa de câmbio média desse período caiu de R $\$ /$ US $\$ 2,18$ para R $\$ /$ US $\$ 1,83$. Essas variações e o fato de grande parte das exportações serem escoadas para a Europa estão orientando os exportadores a estabelecerem contratos em Euro. 
mais passam a ser temporários nos períodos de crise, prejudicando a renda dos trabalhadores e de suas famílias. Além do que, apenas uma parcela dos produtores tem as condições apropriadas para exportar, tais como: tecnologia de irrigação e pós-colheita, custos competitivos, controle de qualidade da produção, variedades consumidas nos principais mercados, capital próprio, logística e articulação com os principais distribuidores. A maioria dos colonos e demais pequenos produtores não possuem, e passam a depender das vendas para os grandes produtores, quando estes necessitam complementar a cota para exportar, ou remetem ao mercado local ou regional.

Se o comércio externo não fosse o principal objetivo das vendas da produção de frutas, dificilmente o volume de recursos públicos despendidos e investimentos privados nas duas últimas décadas seriam justificáveis, principalmente no cultivo de uva, que necessita de um gasto de $\mathrm{R} \$ 40$ a $\mathrm{R} \$ 50$ mil por hectare para ser iniciado. $\mathrm{O}$ crescimento desse APL é atrelado à integração do mercado global e aumento da demanda por frutas tropicais e temperadas de contra-estação. Mas a melhoria das tecnologias de produção (irrigação, manejo, controle de pragas, fertilizantes, defensivos, etc.) e de armazenamento e transporte tem um papel preponderante nesse desenvolvimento.

Direcionar parte da produção para o fluxo interno parece uma alternativa óbvia para diminuir um pouco dessa dependência, não somente para os pequenos produtores, mas, inclusive, para os grandes. É preciso, contudo, deixar de pensar apenas em fluxos e trocas comerciais. A diversificação das culturas e variedades comercializadas também é importante para atender a demandas de consumidores com perfis diferentes tanto no mercado interno quanto estrangeiro e também a integração com a indústria pode promover uma estratégia mais equilibrada do desenvolvimento territorial. Há que se repensar essas ações e estratégias como uma política sistêmica, pois apenas crescimento econômico medido por PIB ou Balança Comercial não garantirá que todos os atores se beneficiem ou prosperem. Até porque deve ocorrer outras melhorias, educacionais, sociais, ambientais, segurança, lazer, etc. 


\section{REFERÊNCIAS}

AGECOM/BA. Vale do São Francisco exporta US\$ 800 milhões por ano (16/07/2009). Disponível em: <http://www.jornalbahiaonline.com.br/index. asp?noticia $=1757>$. Acesso em: 27 nov. 2010.

FAOSTAT. Producción y Comercio. Vários anos. Disponível em: < http:/faostat.fao. org/> . Acesso em: 01 mar. 2010.

FAVERO, L. A. (Org.). A Cultura da manga no São Francisco: posicionamento, limites, oportunidades e ações estratégicas. Fortaleza: Banco do Nordeste do Brasil, 2008.

FUNCKE, A. et al. Novas Commodities (Fruticultura). Sistema Produtivo 04: Projeto Perspectivas do Investimento no Brasil, Rio de Janeiro, 2009. Disponível em: $<$ http://www.projetopib.org/arquivos/04_ds_agronegocio_novas_commodities. pdf>. Acesso em: 23 abr. 2010.

HAESBAERT, R. Dos múltiplos territórios à multiterritorialidade. Porto Alegre, 2004. Disponível em: <http://www6.ufrgs.br/petgea/Artigo/rh.pdf > . Acesso em: 10 abr. 2009.

IBGE. INSTITUTO BRASILEIRO DE GEOGRAFIA E ESTATÍSTICA. Pesquisa Agrícola Municipal (PAM). Rio de Janeiro: vários anos. Disponível em: <www.sidra.ibge. gov.br > . Acesso em: 20 ago. 2009.

LIMA, J. P.; CAMPOS L.; HENRIQUE, R. Inova Nordeste: fruticultura irrigada e vitivinicultura, Relatório de pesquisa, mimeo. Recife, 2005.

MELO, M. A. Crise federativa, guerra fiscal e "Hobbesianismo municipal", efeitos perversos da descentralização? São Paulo em Perspectiva, v. 10, n. 3, 1996.

MOUTINHO, L. M. G. et al. Nota Técnica 4 - Pernambuco - Balanço de pagamentos de Pernambuco: comportamento recente e influências dos principais APLS identificados - FUNPEC/BNDES, 2009. Disponível em: < http://www.politicaapls. redesist.ie.ufrj.br/documentos/getarquivo/arquivo/41 > . Acesso em: 20 abr. 2010. 
NACHREINER, M. L.; BOTEON, M.; PAULA, T. S. Sistema Agroindustrial do Melão: Mossoró versus Juazeiro. In: CONGRESSO BRASILEIRO DE ECONOMIA E SOCIOLOGIA Rural/SOBER, 40., 2002. Anais... Disponível em: < http://cepea.esalq. usp.br/pdf/Melao_Sober.doc >. Acesso em: 04 maio 2010.

PAIVA, C. Á. O que são sistemas locais de produção (e porque eles são tão importantes na estratégia de desenvolvimento do governo democrático e popular no Rio Grande do Sul). In: ENCONTRO DE ECONOMIA GAÚCHA, 1., 2002, Porto Alegre. Anais... Porto Alegre: FEE. Disponível em: < http://www.fee.tche.br/eeg/> Acesso em: 17 jan. 2010.

RUDIO, F. V. Introdução ao projeto de pesquisa científica. 21. ed. Petrópolis: Vozes, 1997. 120p.

SAMPIERI, R. H.; COLLADO, C. F.; LUCIO, P. B. Metodologia de Pesquisa. 3. ed. São Paulo: McGraw-hill, 2006.

SECEX/MDIC. Sistema e Análise das Informações de Comércio Exterior (ALICEWeb) Vários Anos. Disponível em: <http://desenvolvimento.aliceweb.gov.br $>$. Acesso em: 10 set. 2010.

SECTI-BA. SECRETARIA DE CIÊNCIA E TECNOLOGIA E INOVAÇÃO DA BAHIA. Plano de Desenvolvimento do APL de Fruticultura do Vale do São Francisco - Bahia. Salvador-Bahia, 2008. Disponível em: < http://www.mdic.gov.br/arquivos/ dwnl_1247146529.pdf $>$. Acesso em: 12 set. 2010.

SEFAZ-PE/BA - SECRETARIA DA FAZENDA DE PERNAMBUCO E BAHIA. Entradas e Saídas de Manga, Uva, Melão e Coco-da-baía. (2006).

SILVA, P. C. G. Articulação dos interesses públicos e privados no Polo Petrolina-PE/Juazeiro-BA: em busca de espaço no mercado globalizado de frutas frescas. 2001. Tese (Doutorado) - Universidade Estadual de Campinas, Instituto de Economia, Campinas, Disponível em: < http://cutter.unicamp.br/ document $/$ code $=$ vtls000232434\&opt=1>. Acesso em: 11 abr. 2010.

SOUZA, O. C. et al. Aspectos da comercialização do coco no pólo Petrolina (PE) e Juazeiro (BA). In: ENCONTRO DE INICIAÇÃO CIENTÍ́FICA DO IFPI - ENCIPRO, 
2., 2009. Anais eletrônicos... Disponível em: <http://www.ifpi.edu.br/eventos/ iiencipro/arquivos/AGROPECUARIA/831766234a67c105d1792678ae3d5f6a.pdf $>$. Acesso em: 14 nov. 2010.

TAVARES, S. C. C. H.; LIMA, V. C. A indicação geográfica da uva de São Vicente Férrer e Macaparana - PE a partir de pesquisas da Embrapa. Rio de Janeiro, RJ: Ministério da Agricultura, Pecuária e Abastecimento/MAPA, 2009. (Circular Técnica $\mathrm{n}^{\mathrm{O}}$ 43). Disponível em: < http://www.infoteca.cnptia.embrapa.br/bitstream/ doc/664524/1/circtec432009uvasaovicenteferrer.pdf > Acesso em: 17 out. 2010.

VAINER, C. B. As escalas do poder e o poder das escalas: O que pode o poder local?. In: ACSELRAD, H. Planejamento e Território: ensaios sobre a desigualdade. Rio de Janeiro: DP\&A, 2002.

VERGARA, S. C. Projetos e Relatórios de Pesquisa em Administração. São Paulo: Atlas, 1998.

VITAL, T. Vitivinicultura no Nordeste do Brasil: Situação Recente e Perspectivas. Fortaleza: Revista Econômica do Nordeste, v. 40, n. 3, p. 499-524, jul./set. 2009. Disponível em: < http://www.bnb.gov.br/projwebren/exec/artigoRenPDF.aspx?cd_ artigo_ren $=1146>$ Acesso em: 20 mai. 2009.

Recebido: 27 de agosto de 2014 Aceito: 09 de junbo de 2015 